\title{
Lead-binding proteins - a way to understand
} lead toxicity?

\author{
I.A. Bergdahl
}

Department of Occupational and Environmental Medicine, University Hospital, SE-901 85 Umeå, Sweden and Department of Occupational and Environmental Medicine, Lund University, SE-221 85 Lund, Sweden

\begin{abstract}
By the use of LC-ICP-MS, we can find out which proteins bind a toxic metal, and from that understand how enzymatic or other biological processes are affected. The binding of lead to $\delta$ aminolevulinic acid dehydratase (ALAD) in red blood cells is one example of this. Still, the methodology needs further development to allow safer conclusions from the studies.
\end{abstract}

chemists may play a key role in advancing knowledge and understanding.

\section{Lead-binding proteins in human erythrocytes}

This section will focus on lead-binding proteins in human red blood cells (erythrocytes). Studies of lead-binding proteins in kidney have been reviewed elsewhere [3].

The concentration of lead in whole blood is frequently used to monitor exposure to lead, especially in occupationally exposed workers. The studies described below began with the questions: What is monitored, when we determine lead in whole blood? Where in the blood is the lead? Is whole blood the most relevant medium for assessment of exposure and/or risk, or would, for example, plasma analysis be more relevant? Another measure of lead exposure and risk is the activity of the enzyme $\delta$-aminolevulinic acid dehydratase (ALAD) in red blood cells (Fig. 1).

In blood, most of the lead is found in the red blood cells, leaving only in the order of $1 \%$ of the lead in the blood plasma. The proportion of lead in plasma increases with increasing lead concentration, so that a curved relation appears between the concentration in whole blood and that in plasma $[4,5]$. The large difference between the lead concentrations in cells and plasma may be explained by the presence of a protein with high affinity for lead, inside the red blood cells. This high-affinity protein has been presented as being hemoglobin [1], but it has also been proposed that ALAD may be responsible for an appreciable proportion of the lead-binding in red blood cells [6].

We recently studied protein-bound lead in cytosol from red blood cells by LC-ICP-MS [7]. Three lead peaks appeared in the chromatograms, at retention times corresponding to apparent molecular masses of 240, 45 and less than $10 \mathrm{kDa}$, respectively (Fig. 2). Fractions collected from the major peak (at an apparent molecular mass of $240 \mathrm{kDa}$ ) showed ALAD activity (the true molecular mass of ALAD is $280 \mathrm{kDa}$ ). The lead peak disappeared when ALAD was extracted with specific antibodies, thereby confirming that the lead was bound to ALAD [2]. We could thus conclude that the principal lead-binding protein in red blood cells is, in fact, ALAD. No hemoglobin-bound lead was found. The $45 \mathrm{kDa}$ peak is somewhat overlapped by the iron peak for hemoglobin, but the elution profiles for iron and lead differ. The lead signal peaks approximately half a minute later than the iron signal [8].

The finding that lead binds mainly to ALAD, and not to hemoglobin, provides an explanation for a number of phenomena observed in lead toxicity: i) The inhibition of ALAD
This short review paper will deal with lead-binding proteins. The aim is not to describe all the details within the field, but to give an exemple of an area where analytical 


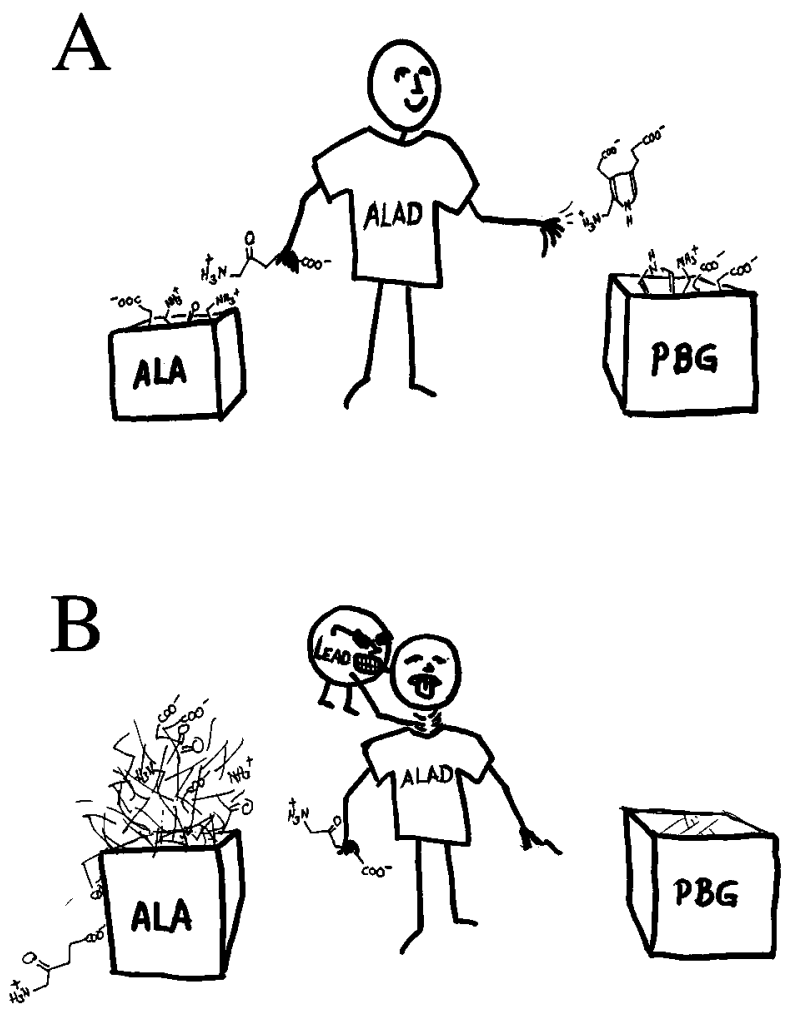

Figure 1. A) $\delta$-aminolevulinic acid dehydratase (ALAD) is the second enzyme in the biochemical pathway for heme synthesis. It catalyzes the condensation of two ALA molecules to one porphobilinogen (PBG) molecule. B) Presence of lead inhibits the activity of ALAD. The inhibition makes it possible to use ALAD activity for biological monitoring of lead exposure.

activity by lead which has been observed in lead-exposed individuals, occurs as a consequence of direct binding of lead to the protein, presumably by binding to sites meant for zinc. ii) The binding of lead to a protein less abundant than hemoglobin, provides an explanation of the curvilinear relation between blood- and plasma-lead concentrations. The curvature can be described by a model based on limited binding capacity for lead-binding proteins [8,9], and the binding capacity in such a model fits well with the erythrocytic concentration of ALAD [8]. iii) It has been suggested that a genetic polymorphism in the human ALAD gene may cause certain individuals to be more sensitive to lead toxicity than others [10-12]. The considerable binding of lead to ALAD may play an important role in the mechanism behind the influence of the ALAD polymorphism on lead toxicity.

The other two lead-binding proteins have not been identified yet. It may be hypothesized that the chromatographic lead peak at $45 \mathrm{kDa}$ reflects lead bound to pyrimidine-5nucleotidase, an erythrocytic enzyme, which is inhibited by lead [13], requires magnesium for its activity, and has an apparent molecular mass of $45 \mathrm{kDa}$ [14].

The smallest of the three proteins (apparent molecular mass $<10 \mathrm{kDa}$, but distinct from the salt peak) is the one which has been the most difficult to study, but which may very well be the most interesting one. The peak area showed an unacceptable variation [7], even in repeats of the same sample. In runs where the peak was large, the recovery could

\section{ICP-MS signal $(\mathrm{Hz})$}

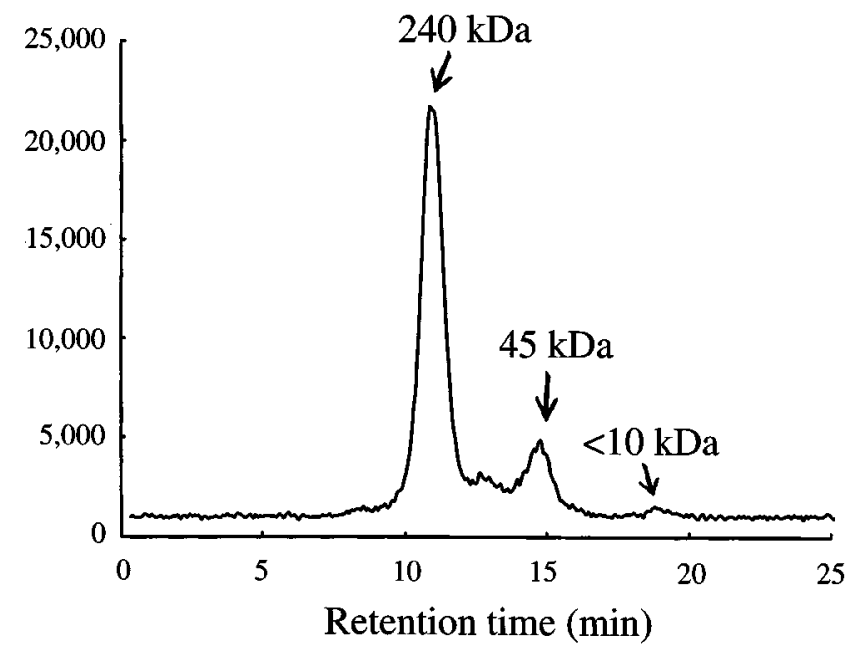

Figure 2. A lead chromatogram from lysed red blood cells. This particular sample was obtained from an individual with moderate lead exposure, having a blood-lead concentration of $115 \mu \mathrm{g} / \mathrm{L}$.

be well above $100 \%$, showing that the lead originated from other sources than the sample itself. The peak was much smaller in a later study [8]. The protein may be the same as that which was reported by Raghavan and Gonick [15], and which has been claimed to be inducible by lead exposure and have a protective effect against lead toxicity [16,17]. An interesting parallel to the small lead-binding protein in red blood cells is a small lead-binding protein found in kidney [18]. The kidney protein has been shown to have the ability to sequester lead from ALAD and partially restitute the activity of lead-inhibited ALAD [19]. The identity of the kidney protein has been reported to be acyl-CoA-binding protein [20]. The acyl-CoA-binding protein is also present in red blood cells [21], and there are indications pointing in the direction that the small lead-binding protein in red blood cells may actually be identical with acyl-CoA-binding protein [12].

\section{Analytical methods}

In early studies, proteins were fractionated on gel chromatography at low pressure. A peristaltic pump or placement of the bottle with the eluent on a shelf above the column provided the pressure necessary to obtain a flow through the column. One separation could take 10-15 hours. Fractions were collected, and lead (or other elements) were determined in the fractions by, for example, atomic absorption spectrometry.

Gercken and Barnes [22] coupled a size exclusion column for HPLC to ICP-MS. Owen et al. [23] used a gel chromatographic column designed for protein separation at a pressure between that of conventional HPLC and conventional gel chromatography coupled directly to ICP-MS. Our setup has been essentially the same as the latter [7].

The use of a chromatographic column will always be afflicted by the suspicion that the separation may alter the 
original composition of the metal species. Further understanding of what happens when metalloproteins are passed through a separation column appears to be very limited. Hypothetically, a number of mechanisms may be involved in the altering of the composition of metal species: i) Equilibria may be altered when metal species are physically separated from each other. The time each separation takes may be of importance, if the kinetics for exchange of the metal is in the same order of magnitude as the separation time. ii) The column matrix may have an affinity for the metal, which can lead to loss of metal and/or transfer of metal between samples. iii) The column may have an affinity for certain parts of the proteins, so that the tertiary structure may be temporarily distorted, leading to loss of coordinated metals and a poor recovery [12].

Despite these suspicions, any protein which binds the metal at the exit from the column will of course have the ability to bind the metal. Under physiological conditions, however, one can not be certain that the partition of the metal between different proteins will be exactly the same.

\section{Discussion}

Several different types of size exclusion columns exist, but the knowledge necessary to make the right choice, and ways to ascertain that errors are not introduced, is sparse. The same holds true for the choice of buffers. In order to find out which chromatographic conditions to use, validation procedures are necessary. Traditionally, biochemistry has been more of a qualitative than quantitative science. Analytical chemistry, on the other hand, is an extremely quantitative discipline. I strongly believe that analytical chemists with their familiarity with recovery, precision, memory effects, representativity, etc., could make important contributions to method validation and development. Such advances would lead to stronger confidence in the methods and, thus, allow safer conclusions from the studies.
Knowledge about protein-binding of toxic metals may lead to understanding of mechanisms for transport and toxic action. Based on the example of ALAD and lead, a model for how metal toxicity can be mediated can be proposed (Fig. 3). It is an open question whether the model may be generalized, or if it describes a part of the mechanism for lead toxicity only.

\section{Acknowledgements}

Görel Svensson is thanked for help with the manuscript. Dr. A. Schütz and Dr. S. Skerfving gave continous support throughout the work described, and the Medical Faculty at Lund University provided financial support.

\section{References}

1. WHO. Environmental health criteria 165 Inorganic lead. Geneva: World Health Organization, 1995.

2. Bergdahl, I. A.; Grubb, A.; Schütz, A.; Desnick, R. J.; Wetmur, J. G.; Sassa, S.; Skerfving, S. Pharmacol. Toxicol. 1997, 81, 153-158.

3. Fowler, B. A. Comments Toxicol. 1989, 3, 27-46.

4. DeSilva, P. E. Br. J. Ind. Med. 1981, 38, 209-217.

5. Bergdahl, I. A.; Schütz, A.; Gerhardsson, L.; Jensen, A.; Skerfving, S. Scand. J. Work Environ. Health. 1997, 23, 359363.

6. Sakai, T.; Yanagihara, S.; Kunugi, Y.; Ushio, K. Br. J. Ind. Med. 1982, 39, 382-387.

7. Bergdahl, I. A.; Schütz,A.; Grubb, A. J. Anal. Atom. Spectrom. 1996, 11, 735-738.

8. Bergdahl, I. A.; Sheveleva, M.; Schütz, A.; Artamonova, V. G.; Skerfving, S. Tox. Col. Sci., in press.

9. O’Flaherty, E. J.; Inskip, M. J.; Yagminas, A. P.; Franklin, C. A. Toxicol. Appl. Pharmacol. 1996, 138, 121-130.

10. Wetmur, J. G.; Lehnert, G.; Desnick, R. J. Environ. Res. 1991, 56, 109-119.

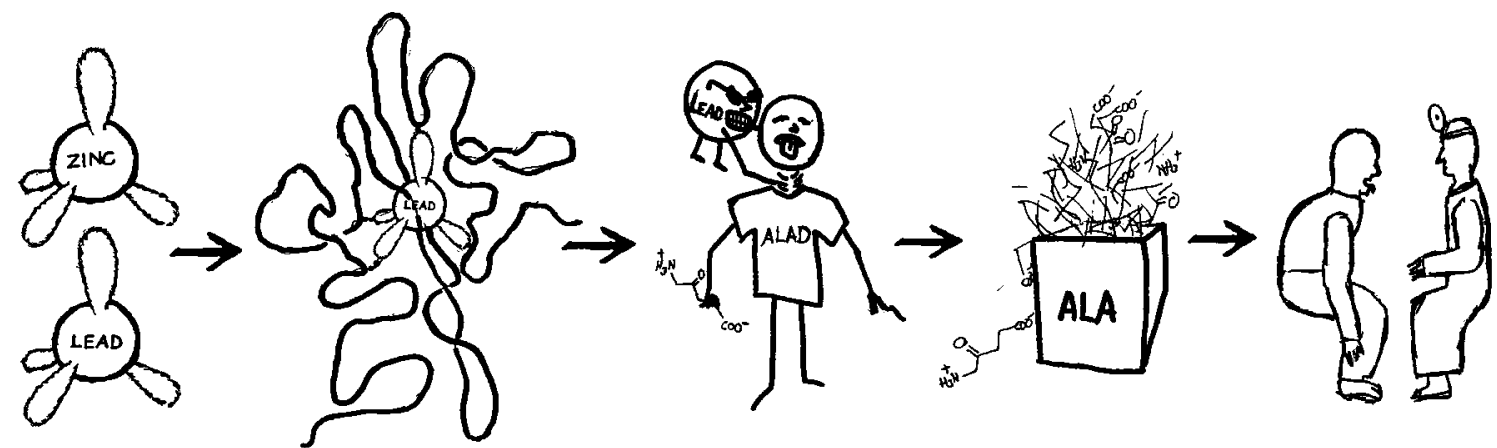

\begin{abstract}
Physico-chemical similarity between essential and toxic metal
\end{abstract}

Binding of the toxic metal to a protein site intended for the essential metal
Inhibition of e.g. enzymatic activity of the protein
Deficiency or
Disease
excess of a
specific
biomolecule

Figure 3. Illustration of a model proposed for the mechanism of lead toxicity. 
11. Bergdahl, I. A.; Gerhardsson, L.; Schütz, A.; Desnick, R. J.; Wetmur, J. G.; Skerfving, S. Arch. Environ. Health. 1997, 52, 91-96.

12. Bergdahl, I. A. Lead in blood. ICP-MS studies of lead in plasma, blood and erythrocyte proteins [thesis] Department of Occupational and Environmental Medicine, Lund University, 1997.

13. Paglia, D. E.; Valentine, W. N.; Fink, K. J. Clin. Invest. 1977, 60, 1362-1366.

14. Amici, A.; Emanuelli, M.; Ferretti, E.; Raffaelli, N.; Rug gieri, S.; Magni, G. Biochem. J. 1994, 304, 987-992.

15. Raghavan, S. R. V.; Gonick, H. C. Proc. Soc. Exp. Biol. Med. 1977, 155, 164-167.

16. Raghavan S. R. V.; Culver, B. D.; Gonick, H. C. Environ. Res. 1980, 22, 264-270.
17. Lolin, Y.; O’Gorman, P. Ann. Clin. Biochem. 1988, 25, 688697.

18. Oskarsson, A.; Squibb, K. S.; Fowler, B. A. Biochem. Biophys. Res. Communic. 1982, 104, 290-298.

19. Goering, P. L.; Fowler, B. A. J. Pharmacol. Exp. Ther. 1984, 231, 66-71.

20. Smith, D. R.; Kahng, M. W.; Quintanilla, B.; Fowler, B. A. [abstract] Toxicologist 1994, 14, 84.

21. Fyrst, H.; Knudsen, J.; Schott, M. A.; Lubin, B. H.; Kuypers, F. A. Biochem. J. 1995, 306, 793-799

22. Gercken, B.; Barnes, R. M. Anal. Chem. 1991, 63, 283-287.

23. Owen, L. M. W.; Crews, H. M.; Hutton, R. C.; Walsh, A. Analyst 1992, 117, 649-655. 